\title{
LEVANTAMENTO EPIDEMIOLÓGICO EM ESCOLA PÚBLICA DE CASCAVEL
}

Sávio BRANDELERO JUNIOR, Mariângela Monteiro de Melo BALTAZAR

O presente trabalho retrata a situação de saúde bucal das crianças de 5 a 11 anos na Escola Municipal Irene Rickle no município de Cascavel, PR, por meio de levantamento epidemiológico realizado por alunos da segunda série do curso de odontologia da UNIOESTE nos anos de 2006 e 2007. Este estudo teve como objetivo principal colocá-los em contato com os conhecimentos de epidemiologia, planejamento e avaliação em saúde. Antes de sair a campo, os acadêmicos foram calibrados para apresentar consistência nos julgamentos clínicos. Os objetivos da calibração seriam o de assegurar a uniformidade de interpretação, compreensão e aplicação dos critérios para as condições a serem observadas e registradas. Todos os resultados apontados aqui foram extraídos pelos alunos em suas atividades práticas cotidianas da Disciplina de Odontologia em Saúde Coletiva II e aponta para uma grave situação de saúde bucal para a população em questão. Como principal resultado tem-se o aprendizado da epidemiologia e planejamento em saúde, e o apontamento mais importante é que ocorre uma falta de atenção odontológica para a população estudada tanto no aspecto de ações individuais e curativas, como também das ações coletivas de promoção de saúde. 